\title{
COMPORTAMENTO OPERACIONAL DE UM ESCARIFICADOR DE HASTES PARABÓLICAS EM SOLO DE CERRADO
}

\author{
Aloisio Bianchini' ${ }^{1}$, Marcos H. C. Sabino ${ }^{2}$, Pedro H. M. Borges $^{3}$ \& José Jonas Sguarezzi ${ }^{4}$
}

\begin{abstract}
RESUMO
O escarificador é um importante implemento de preparo primário de solo, embora nem sempre utilizado nos cerrados de forma correta, em função do pouco conhecimento que se tem a respeito de seu comportamento. Assim, instalou-se, na Escola Agrotécnica Federal de Cuiabá, um experimento com o objetivo de se avaliar o desempenho de um escarificador de hastes parabólicas no preparo primário de um solo de cerrado e obter equações que possam prever a força de tração e a potência exigidas; a área constituía-se de um Latossolo Vermelho-Amarelo, com 14,3\% de argila, de cobertura vegetal média de $9.975 \mathrm{kgha}^{-1}$ de matéria seca e de um teor médio de umidade de $13 \%$. Os resultados obtidos mostram que os parâmetros força de tração, área mobilizada e resistência específica, não sofreram influência com a variação da velocidade, a potência aumentou e a energia consumida $\left(\mathrm{kWh} \mathrm{ha}^{-1}\right)$ diminuiu com o aumento da velocidade. A força de tração, a potência na barra e a resistência específica do solo apresentaram comportamento quadrático, em função da profundidade de preparo. A área de seção transversal de solo mobilizado apresentou comportamento linear com a variação da profundidade de operação do escarificador. A melhor eficiência, de 85,69\%, foi obtida para a relação largura/profundidade de operação igual a 1,23, e a equação de McKeys, com o fator de correção de 1,08, foi eficiente para predizer a área mobilizada efetiva.
\end{abstract}

Palavras-chave: força de tração, potência, área mobilizada, eficiência

\section{PERFORMANCE OF A PARABOLIC CHISEL PLOW IN A SOIL OF “CERRADO”}

\begin{abstract}
The chisel plow is an important implement for tillage, but it is not always used correctly in the "Cerrados", due to limited availability of knowledge on the behavior of the chisel plow in these soils. An experiment was set up at the "Escola Agrotécnica Federal de Cuiabá" with the objective of evaluating the action of a chisel plow, with a parabolic stem, in "Cerrado" soil. The plots were set on a "Latossolo Vermelho-Amarelo", with $14.3 \%$ clay, under a mulch blanketing of $9.975 \mathrm{kgha}^{-1}(\mathrm{DM})$ and $13 \%$ soil moisture. The results show that the mobilized area and the specific resistance were not influenced by speed variation. The power increased and the energy consumption $\left(\mathrm{kWh} \mathrm{ha}^{-1}\right)$ decreased with the increase of the speed. The pull traction, power and the soil specific resistance varied quadratically with tillage depth, while the cross section at area of mobilized soil presented a linear behavior. The best efficiency of $85.69 \%$, was obtained for the relation width/depth $=1.23$. The equation of McKeys, with a correction factor of 1.08 , was efficient for the prediction of the effectively mobilized area.
\end{abstract}

Key words: pull traction, power, mobilized area, efficiency

\footnotetext{
${ }^{1}$ Prof. Assistente M.Sc., Departamento de Solos e Eng. Rural -FAMEV/UFMT, CEP 78060 - 900, Cuiabá, MT, Fone: (065) 6158601

${ }^{2}$ Aluno de Agronomia - FAMEV/UFMT. Bolsista de Iniciação Científica

${ }^{3}$ Prof. Adjunto Dr., Departamento de Engenharia, UFLA, Lavras, MG, Fone: (035) 8291481

${ }^{4}$ Agrônomo, Técnico Nível Superior. Depto de Solos e Eng. Rural - FAMEV/UFMT, Cuiabá, MT
} 


\section{INTRODUÇÃO}

Os cerrados mato-grossense apresentam, na sua maioria, topografia suave e solos profundos, sem impedimento físico (Maia, 1990) possibilitando a utilização da mecanização intensiva em grandes áreas. Somente no ano agrícola 1993/94, a área cultivada no Estado de Mato Grosso foi da ordem de 3,197 milhões de hectares (Fundação IBGE, 1994) o que pode ser considerado um avanço enorme, uma vez que há três décadas a agricultura intensiva era, no Estado, praticamente inexistente .

A utilização da mecanização agrícola sem critério pode trazer grandes problemas ao meio ambiente, colocando em risco a sustentabilidade de um sistema produtivo; a desestruturação do solo é um exemplo, pois acarreta mudanças indesejáveis nas suas propriedades físicas, evidenciadas pela compactação, e é consequiência, de acordo com Silva et al. (1986) da mecanização excessiva, do uso de equipamentos pesados e, principalmente, do preparo do solo realizado em condições de umidade inadequada.

Segundo Mantovani (1987) a exploração de grandes áreas requer alta capacidade efetiva de trabalho $\left(\mathrm{ha} \mathrm{h}^{-1}\right)$ dos equipamentos agrícolas e, conseqüentemente, o uso de alguns implementos, como a grade pesada, que tem sido uma constante no preparo do solo e, nesta situação, a eficiência de trabalho aumenta em detrimento da qualidade do manejo do solo.

O escarificador é um implemento agrícola que se apresenta, neste cenário, como opção para o agricultor, dentro da ótica do manejo conservacionista; ele traz, como vantagens, o fato de que mobiliza o solo sem revolvê-lo, promovendo a incorporação de menos de $1 / 3$ do material existente na superfície (OrtizCañavate \& Hernanz, 1989) além de agredir pouco a estrutura do solo, por produzir torrões grandes (fissuras pouco numerosas, porém de grandes extensões). Este implemento consegue romper camadas compactadas do solo e atingir profundidades de trabalho maiores, quando comparado com outros implementos de preparo primário.

A escassez de dados de pesquisa para orientar técnicos e agricultores conduz à realização de atividades do processo produtivo, principalmente aquelas relacionadas ao preparo do solo, sem muito critério científico. O preparo dos solos dos cerrados poderá ser realizado com maior eficiência, desde que os agricultores disponham de informações técnicas sobre o comportamento dos diversos implementos por eles utilizados, geradas por pesquisas especificas para a região, em particular as relacionadas à interação solo-máquina.

$\mathrm{O}$ comportamento dos escarificadores, no que se refere à interação solo-máquina, é pouco conhecido, em se tratando de solos de cerrados brasileiros, e pode ser avaliado em função da resistência específica do solo à ação da haste escarificadora, da área de solo mobilizada pelo implemento e pela relação entre a área teórica e a área real mobilizada (eficiência na mobilização do solo).

O presente trabalho foi conduzido na Escola Agrotécnica de Cuiabá, com o objetivo de avaliar a influência da profundidade de operação e da velocidade de deslocamento no comportamento de um escarificador, em trabalho de preparo primário do solo, em área de cerrados, e se obter equações que possam predizer a força de tração e a potência requeridas para o escarificador em estudo.

\section{MATERIAL E MÉTODOS}

\section{Caracterização da área experimental}

O campo experimental foi instalado na Escola Agrotécnica Federal de Cuiabá, em área com vários anos de cultivo, cujo solo foi classificado como Latossolo Vermelho-Amarelo, francoarenoso, apresentando granulometria média de $70,93 \%$ de areia, $14,77 \%$ de silte e $14,3 \%$ de argila.

O solo da área experimental se encontrava, durante os ensaios, relativamente seco, com umidade de $14 \%$ na camada 0 - $20 \mathrm{~cm}$ de profundidade e a umidade obtida para a capacidade de campo do solo foi de $17,7 \%$.

A área do experimento foi previamente roçada e apresentava cobertura vegetal média de $9.976 \mathrm{~kg} \mathrm{ha}^{-1}$ de matéria seca, constituída basicamente de restos culturais de milho e de gramíneas infestantes. Apresentava, também, uma camada de solo mais compactada, entre 150 e $350 \mathrm{~mm}$ de profundidade, detectada por meio de um penetrômetro de impacto, modelo IAA/Planalsucar-Stolf, adotando-se metodologia descrita por Stolf et al. (1983).

\section{Delineamento estatístico, equipamento e coleta de dados}

$\mathrm{O}$ delineamento adotado foi o inteiramente casualizado, com parcelas úteis de $50 \mathrm{~m}$ de comprimento e aproximadamente $2,5 \mathrm{~m}$ de largura. A análise dos dados seguiu o esquema fatorial (5 x 2) onde 5 representa os intervalos de profundidade $(125,175,225$, 275 e $325 \mathrm{~mm}), 2$ as velocidades de deslocamento do conjunto trator-escarificador $\left(1,0\right.$ e $\left.1,6 \mathrm{~m} \mathrm{~s}^{-1}\right)$ e três repetições, perfazendo o total de 30 parcelas experimentais.

O escarificador de arrasto utilizado foi o Jumbo Matic*, com 7 hastes de formato parabólico e ponteira em cinzel, com $70 \mathrm{~mm}$ de largura e $22^{\circ}$ de ângulo de ataque, além de tracionado por um trator de $75,7 \mathrm{~kW}$ de potência nominal no motor e tração dianteira assistida. Para a coleta de dados montaram-se apenas três hastes do escarificador, sendo uma na seção dianteira e as outras duas na seção traseira, guardando entre elas o espaçamento de $400 \mathrm{~mm}$.

Para se analisar o comportamento do escarificador, foram coletados dados de força de tração, tempo e área transversal de solo mobilizado. O dinamômetro com a célula de carga utilizado na coleta de dados, foi previamente aferido para forças de tração, em uma Máquina Universal de Teste - Tipo RAT, com capacidade de até 294 kN, apresentando uma equação de correlação com um $\mathrm{R}^{2}=0,9999$, para o intervalo de 0 a $24,5 \mathrm{kN}$.

Os dados de força de tração foram coletados a cada $2 \mathrm{~s}$, por meio do dinamômetro instalado na barra de tração do trator; os primeiros e os últimos valores coletados foram desprezados e, com o restante dos dados, obteve-se um valor médio, que passou a representar a força média obtida nas parcelas, enquanto a potência média requerida pelo escarificador foi calculada utilizando-se os dados obtidos em cada parcela, para força média, e o tempo gasto para o conjunto transladar os $50 \mathrm{~m}$ úteis da parcela.

\footnotetext{
* A referência pelo nome do produto é somente para informação específica e não implica na sua aprovação ou recomendação por parte dos autores ou pela FAMEV/UFMT, em exclusão de outros que lhe são similares
} 
A área de seção transversal de solo efetivamente mobilizada pelo implemento foi obtida medindo-se, perpendicularmente à passada, de $100 \mathrm{em} 100 \mathrm{~mm}$, as profundidades até onde o escarificador conseguiu perturbar o solo e, para tanto, retirouse todo o solo mobilizado em uma faixa de $1 \mathrm{~m}$ transversalmente à passada do implemento. Duas seções foram levantadas em cada repetição de cada tratamento e adotou-se a média obtida do cálculo da área de seção de solo mobilizada, por meio da integração pelo método dos trapézios; a resistência específica do solo pôde, então, ser calculada, por meio dos dados de força e a da área de seção mobilizada em cada parcela.

A eficiência de mobilização do escarificador, aqui definida como sendo a razão entre a área teórica e a área efetivamente mobilizada, também foi determinada; a área teórica de mobilização foi calculada considerando-se a área inscrita em um trapézio, cuja base maior era a largura efetiva de trabalho do implemento $(1,2 \mathrm{~m})$ e a altura do trapézio foi representada pela profundidade de trabalho do implemento. Os ângulos agudos internos do trapézio considerado, determinados de acordo com McKyes (1985) para as profundidades de 125 a $325 \mathrm{~mm}$, variando de 50 em $50 \mathrm{~mm}$, foram de $32^{\circ}, 41,2^{\circ}, 48,4^{\circ}, 54^{\circ} \mathrm{e} 58,4^{\circ}$.

\section{RESULTADOS E DISCUSSÃO}

As velocidades de deslocamento do conjunto trator + escarificador apresentaram médias de $1,02( \pm 0,016)$ e 1,58 $( \pm 0,027)$ e os coeficientes de variação obtidos foram de $6,16 \%$ e $6,71 \%$, respectivamente, considerados baixos, segundo Gomes (1990). Esses resultados permitem afirmar que as velocidades preestabelecidas ( 1 e $1,6 \mathrm{~m} \mathrm{~s}^{-1}$ ) foram praticamente atingidas e que o seu controle, durante os ensaios, foi eficiente, permitindo a realização das análises estatísticas sem problemas.

A análise de variância da regressão dos resultados para a força de tração na barra do trator, a área de seção transversal de solo mobilizado, resistência específica do solo à mobilização e a eficiência do escarificador no trabalho de mobilização, são apresentados na Tabela $1 \mathrm{e}$, para a potência requerida na barra de tração do trator, na Tabela 2.
Tabela 2. Resumo das análises de variâncias da regressão das potências requeridas pelo escarificador nas velocidades de deslocamento do conjunto de 1 e $1,6 \mathrm{~m} \mathrm{~s}^{-1}$

\begin{tabular}{lccc}
\hline Fonte de Variação & GL & \multicolumn{2}{c}{ Quadrados Médios } \\
\cline { 3 - 4 } & & Velocidade de 1 $\mathrm{m} \mathrm{s}^{-1}$ & Velocidade de $1,6 \mathrm{~m} \mathrm{~s}^{-1}$ \\
\hline Profundidade & 4 & $175,3387 * *$ & $536,7424 * *$ \\
Linear & 1 & $641,1749 * *$ & $1956,072 * *$ \\
Quadrática & 1 & $45,13271 *$ & $138,8592 *$ \\
Cúbica & 1 & $12,64957^{\mathrm{ns}}$ & $51,53009^{\mathrm{ns}}$ \\
Quarto grau & 1 & $2,396794^{\mathrm{ns}}$ & $0,5080304^{\mathrm{ns}}$ \\
Resíduo & 10 & 5,343970 & 7,363403 \\
\hline C.V. $(\%)$ & & 14,28 & 11,43 \\
\hline
\end{tabular}

Obs.: ns, * e ** representam, respectivamente, não significativo e significativo a nível de 5 e a $1 \%$ de probabilidade, pelo teste $\mathrm{F}$

As análises de variância da regressão demonstram que a velocidade de deslocamento do conjunto não foi significativa entre os dois níveis estudados para a força de tração, área mobilizada, resistência específica e eficiência do escarificador (Tabela 1).

Como havia apenas dois níveis de velocidade, analisou-se somente o efeito linear desta variável. Owen (1989) no entanto, observou o efeito da velocidade na força de tração, quando analisou a influência da velocidade de operação, entre 0,1 e $2 \mathrm{~m} \mathrm{~s}^{-1}$, nas forças atuantes e na área mobilizada de uma ferramenta de escarificador, que trabalhava a $450 \mathrm{~mm}$ de profundidade; segundo o autor, o efeito é quadrático na força total de tração requerida e na resistência específica do solo, porém pequeno.

Os resultados obtidos para área de seção transversal de solo mobilizado concordam com McKyes (1985) que afirma não haver, ainda, evidências para confirmar se esta área varia apreciavelmente com a velocidade de operação; concordam, também, com o trabalho de Owen (1989) concluindo que a velocidade na faixa de 0,1 a $2 \mathrm{~m} \mathrm{~s}^{-1}$, não influenciou a área de seção transversal de solo mobilizado.

Os resultados para a força total de tração demostraram que ela é afetada pela profundidade de operação do escarificador. A resposta é quadrática (Figura 1) com coeficiente de determinação elevado $(0,92)$ que permite utilizar-se a equação de regressão levantada, $\mathrm{F}=3.231,33-25,13 \mathrm{p}+0,1 \mathrm{p}^{2}$ (com $\mathrm{F}$, força por haste,

Tabela 1. Resumo da análise de variância da regressão para a força de tração e potência requeridas, área mobilizada, resistência específica do solo e eficiência do escarificador

\begin{tabular}{|c|c|c|c|c|c|}
\hline \multirow{2}{*}{$\begin{array}{l}\text { Fontes de } \\
\text { Variação }\end{array}$} & \multirow[t]{2}{*}{ G L } & \multicolumn{4}{|c|}{ Quadrados Médios } \\
\hline & & Força & Área & Resistência Específica & Eficiência Escarificador \\
\hline Velocidade (v) & 1 & $16663,51^{\mathrm{ns}}$ & $891,07 \mathrm{~ns}$ & $0,01903 \mathrm{~ns}$ & $1,4170^{\mathrm{ns}}$ \\
\hline Linear & 1 & $16663,51 \mathrm{~ns}$ & $891,07 \mathrm{~ns}$ & $0,01903 \mathrm{~ns}$ & $1,4170 \mathrm{~ns}$ \\
\hline Profundidade $(\mathrm{p})$ & 4 & $2477801,00^{* *}$ & $2912277,00^{* *}$ & $0,06854^{* *}$ & $66,6017^{\mathrm{ns}}$ \\
\hline Linear & 1 & $9253526,00^{* *}$ & $11575990,00^{* *}$ & $0,22510^{* *}$ & $253,8749^{*}$ \\
\hline Quadrático & 1 & $626640,70^{* *}$ & $46930,00^{\mathrm{ns}}$ & $0,04614^{*}$ & $0,0144^{\mathrm{ns}}$ \\
\hline Cubico & 1 & $11325,61 \mathrm{~ns}$ & $9163,48 \mathrm{~ns}$ & $0,00147 \mathrm{~ns}$ & $3,4034 \mathrm{~ns}$ \\
\hline Quarto grau & 1 & $19702,16^{\mathrm{ns}}$ & $17017,03 \mathrm{~ns}$ & $0,00147 \mathrm{~ns}$ & $9,1141 \mathrm{~ns}$ \\
\hline $\mathrm{v} \times \mathrm{p}$ & 4 & $80391,63 \mathrm{~ns}$ & $16550,35 \mathrm{~ns}$ & $0,01860 \mathrm{~ns}$ & $19,0075^{\mathrm{ns}}$ \\
\hline Resíduo & 20 & 24133,60 & 52706,75 & 0,00829 & 46,9160 \\
\hline C. V. $(\%)$ & & 13,16 & 12,14 & 15,21 & 8,39 \\
\hline
\end{tabular}




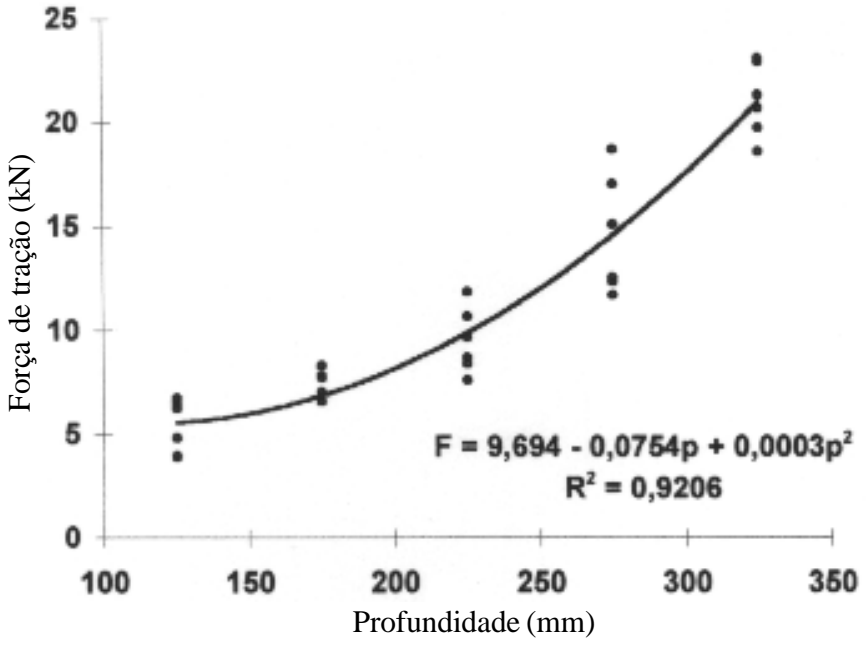

Figura 1. Força de tração líquida $(\mathrm{F}, \mathrm{em} \mathrm{kN})$ exigida na barra de tração do trator, em função da profundidade de trabalho do escarificador (p, em mm) com 3 hastes espaçadas de $400 \mathrm{~mm}$

em $\mathrm{N}$ e p, profundidade, em $\mathrm{mm}$ ) para a predição da força requerida por um escarificador em condições similares à do experimento, desde que corrigida para o número de hastes a ser usado. Deve-se lembrar, então, que a equação apresentada foi obtida com o escarificador, trabalhando com três hastes. Várias referências demonstram que a variação da força de tração, em função da profundidade de trabalho, é representada por uma expressão quadrática (Kiss \& Bellow, 1981; Perumpral et al., 1983 e American Society of Agricultural Engineer, 1990).

O coeficiente quadrático da expressão obtida para a força de tração na barra é pequeno, da ordem de 0,1 ; no entanto, significativo a nível de 0,01 de probabilidade. Silva et al. (1984) realizaram um estudo utilizando três tipos de haste subsoladora, trabalhando na profundidade de 10 a $60 \mathrm{~cm}$, em Latossolo Vermelho-Amarelo, fase terraço, do Estado de São Paulo, com $40 \%$ de argila, em que os resultados demonstraram que os efeitos linear e quadrático da profundidade de operação na força de tração foram significantes, mas se percebe que os coeficientes quadráticos, por eles encontrados, são também pequenos.

A força de tração média obtida para o escarificador estudado, na profundidade máxima de $325 \mathrm{~mm}$, foi de $21,023 \mathrm{kN}$, que é muito superior aos $4,554 \mathrm{kN}$ encontrados para a profundidade mínima de $125 \mathrm{~mm}$, demonstrando que o coeficiente quadrático da profundidade de operação não pode ser desprezado, mesmo que pequeno. Grandes variações na força de tração podem ser obtidas com pequenas variações de profundidade de operação dos escarificadores, como os resultados obtidos por Bianchini et al. (1996) em trabalho realizado em solo aluvial, com aproximadamente $60 \%$ de argila, que obtiveram variação significativa na força de tração, de $12,77 \mathrm{kN}$ para $18,16 \mathrm{kN}$, quando a profundidade de trabalho de um escarificador de cinco hastes variou apenas $60 \mathrm{~mm}$ (de 270 para $330 \mathrm{~mm}$ ).

A análise da potência exigida na barra de tração foi realizada separadamente para cada velocidade, como mostra a Figura 2 na qual se observa claramente o efeito do aumento da velocidade de deslocamento, quando se compara a tendência das duas curvas. Para a velocidade de $1,6 \mathrm{~m} \mathrm{~s}^{-1}$, a potência requerida na barra apresentou valor médio de $7,02 \mathrm{~kW}$, bastante próximo da média obtida para a velocidade de $1 \mathrm{~m} \mathrm{~s}^{-1}$, que ficou em 7,32 kW.

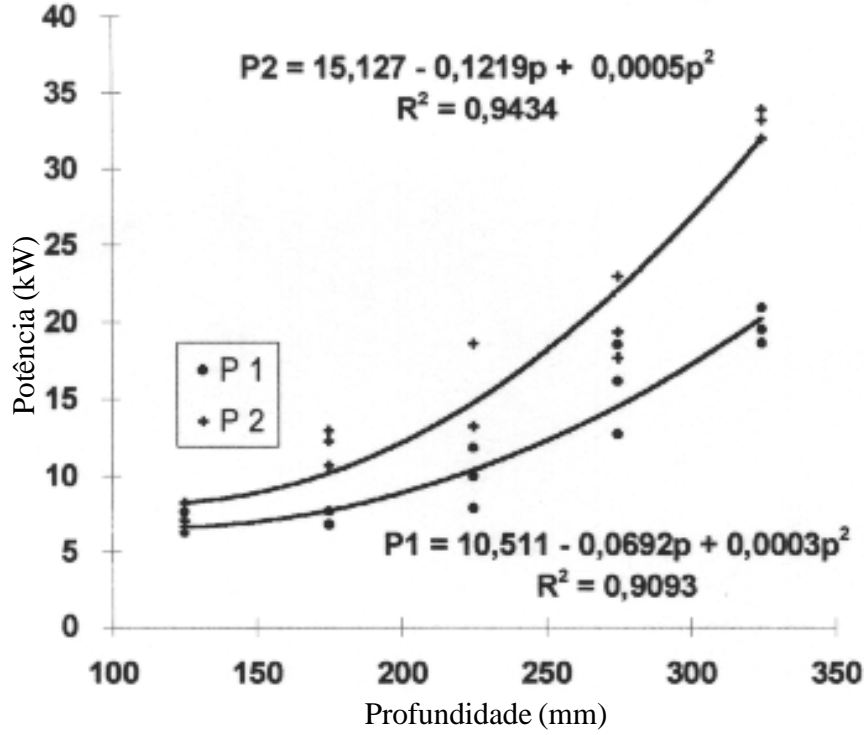

Figura 2. Potência $(\mathrm{kW})$ requerida pelo escarificador, para diferentes velocidades em função da profundidade de trabalho ( $\mathrm{p}, \mathrm{em} \mathrm{mm}$ ) com 3 hastes espaçadas $400 \mathrm{~mm}$

Com o aumento da profundidade, a diferença de potência exigida para as duas velocidades, que era de apenas $0,3 \mathrm{~kW}$, foi crescendo rapidamente, até atingir $18,14 \mathrm{~kW}$, na profundidade de $325 \mathrm{~mm}$.

Bianchini et al. (1996) encontraram diferenças significativas entre os valores de $17,91 \mathrm{~kW}$ e 22,02 $\mathrm{kW}$ para a potência, quando a profundidade de trabalho variou de 270 para $330 \mathrm{~mm}$.

A quantidade de energia média consumida pelo escarificador, calculada usando-se a largura de corte de $1,2 \mathrm{~m}$, foi de $27,67 \mathrm{kWhha}^{-1}$ para a velocidade de $1 \mathrm{~m} \mathrm{~s}^{-1}$ e de $25,27 \mathrm{kWh} \mathrm{ha}^{-1}$ para a velocidade de $1,6 \mathrm{~m} \mathrm{~s}^{-1}$ (8,7\% inferior); esses valores são estatisticamente diferentes pelo teste t-student, a nível de 0,05 de probabilidade, e mostram, ainda, que a energia requerida na barra de tração do trator, para preparar 1 ha de solo, diminuiu com o acréscimo da velocidade. Fica evidente, desta forma, a importância do fator velocidade no planejamento da operação de escarificação, não só pelo aumento da capacidade operacional mas, também, pela redução da energia gasta no processo. O tempo de operação necessário para se preparar 1 ha de solo foi reduzido em $62 \%$, quando a velocidade foi alterada de 1 para $1,6 \mathrm{~m} \mathrm{~s}^{-1}$ e a energia disponível para o trabalho foi melhor aproveitada, apresentando redução de 6,8 \%.

A Figura 3 mostra o comportamento da resistência específica do solo e a equação obtida pela regressão, a partir dos valores médios, e os valores observados (os valores são relativos ao trabalho de três hastes em conjunto). A resistência específica do solo aumentou em função do incremento, na profundidade de trabalho do escarificador, sendo que os valores extremos obtidos foram de $50,57 \mathrm{kN} \mathrm{m}^{-2}$, para a profundidade de $125 \mathrm{~mm}$, e de $75,55 \mathrm{kNm}^{-2}$ para a profundidade de $325 \mathrm{~mm}$.

A análise de variância para a resistência específica do solo, Tabela 1, mostra que o efeito linear e o quadrático também se apresentaram significantes para o fator profundidade de trabalho. Este comportamento seguiu a tendência dos dados de força de tração (comportamento quadrático) por ser diretamente proporcional, considerando-se que a área de solo mobilizada 


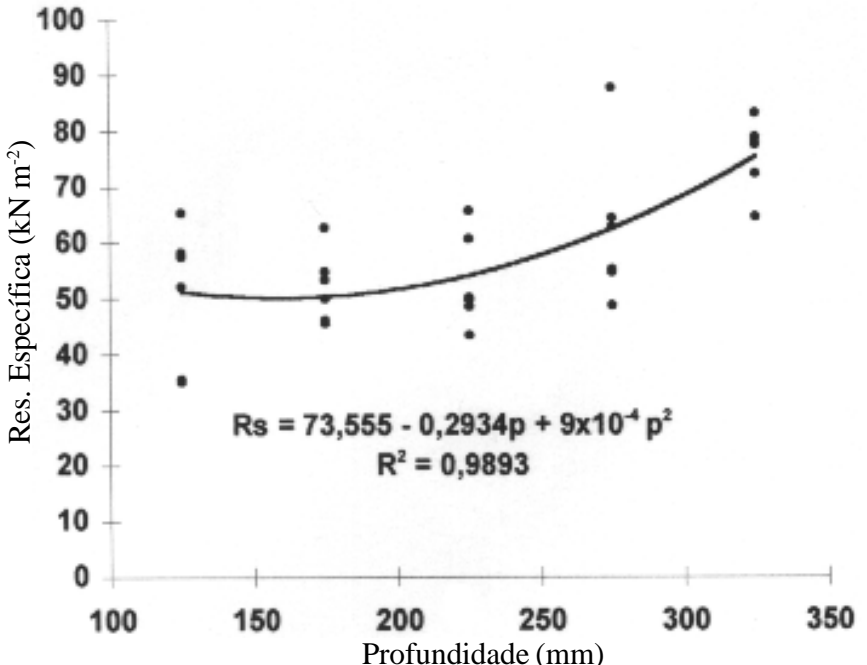

Figura 3. Resistência específica do solo média ( $\mathrm{Rs}$, em $\mathrm{kN} \mathrm{m}^{-2}$ ), em função da profundidade de trabalho do escarificador (p, em mm) com 3 hastes espaçadas de $400 \mathrm{~mm}$

(Figura 4) e inversamente proporcional, apresentou comportamento linear e crescente.

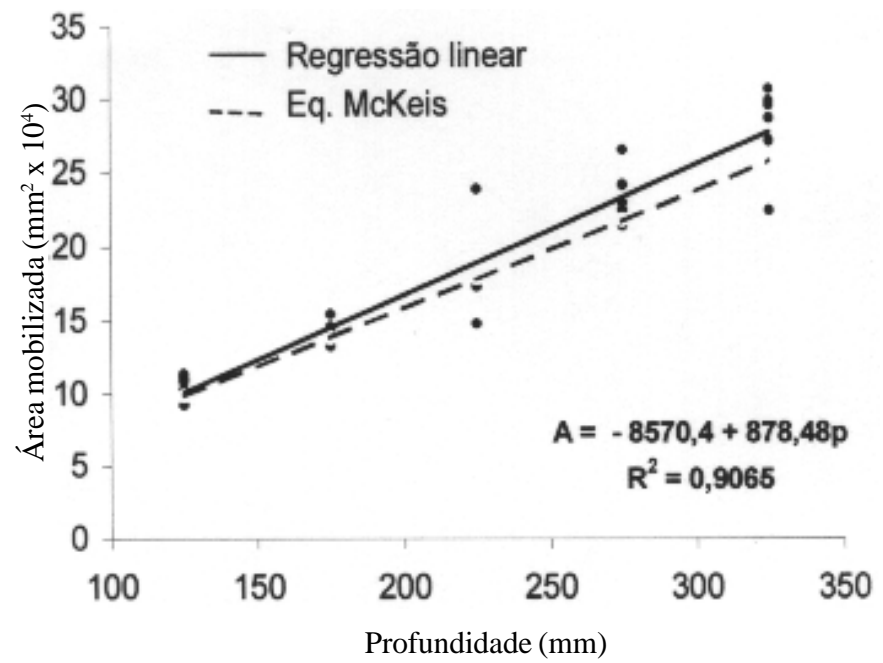

Figura 4. Área de solo mobilizada pelo escarificador $\left(\mathrm{A}, \mathrm{em} \mathrm{mm}^{2}\right)$ em função da sua profundidade de trabalho ( $\mathrm{p}, \mathrm{em} \mathrm{mm}$ ) com 3 hastes espaçadas de $400 \mathrm{~mm}$

Figueiredo (1994) realizou um trabalho em Latossolo roxo, com $82 \%$ de argila usando velocidades de operação em torno de $1,55 \mathrm{~m} \mathrm{~s}^{-1}$ e quatro tipos diferentes de haste; entre elas, foi testada a haste modelo Jumbo, que é o mesmo modelo utilizado no presente trabalho; o valor de resistência específica do solo por ele obtido foi de $87,6 \mathrm{kNm}^{-2}$.

Spoor \& Godwin (1978) realizaram trabalho com um escarificador, com hastes espaçadas $50 \mathrm{~cm}$, nas profundidades de operação de 160 e $240 \mathrm{~mm}$, em caixa de solo utilizando solos com teor de argila em torno de $40 \%$. Os resultados da resistência específica encontrados decresceram com o aumento da profundidade de operação $\left(90 \mathrm{kN} \mathrm{m}^{-2}\right.$ para $\left.74 \mathrm{kN} \mathrm{m}^{-2}\right)$ fato este devido ao aumento da área mobilizada $\left(0,238 \mathrm{~m}^{2}\right.$ para $\left.0,283 \mathrm{~m}^{2}\right) \mathrm{e}$ uma variação não significativa na força de tração.

No presente trabalho a denominada profundidade crítica de sub-solagem não foi atingida. De acordo com Godwin \& Spoor
(1977) apud Portela et al. (1994), ela fica em torno de 7 vezes a largura da ponteira da haste e é definida como sendo aquela a partir da qual o esforço tratório cresce sem um incremento significativo na área de solo mobilizado. A ponteira da ferramenta utilizada tinha $70 \mathrm{~mm}$ de largura, o que resultaria em uma profundidade crítica em torno de $490 \mathrm{~mm}$; a maior profundidade de ensaio foi de $325 \mathrm{~mm}$ e o aumento da área mobilizada pelo escarificador foi linear (Figura 4). Este comportamento linear significativo permite afirmar que a profundidade crítica não foi atingida pois, do contrário, a tendência da curva não seria linear.

McKeys (1985) apresenta a seguinte equação para o cálculo da área efetivamente mobilizada pelo escarificador (Ad) em função da profundidade de trabalho (d), da distância entre hastes (sp), do ângulo do talude (n) e da largura da ferramenta (w) que doravante, será denominada EAP (Equação da Estimativa da Área Perturbada):

$$
A d=d . s p-0,25 .(s p-w) 2 \cdot \tan n
$$

Quando se comparou os dados das áreas mobilizadas obtidas no trabalho com os valores calculados pela EAP, obteve-se uma alta correlação $(r=0,997)$. A equação de regressão obtida para os dados de campo mostra uma diferença sempre crescente com a profundidade, em relação aos valores de área mobilizada obtidos pela EAP (Figura 4).

As diferenças entre os valores calculados pela EAP e os obtidos no experimento existem porque a EAP considera uma área triangular não mobilizada (A1) entre as hastes escarificadoras, que não existe, como fica evidenciado na Figura 5. Ela mostra, a título de exemplo, o perfil médio do solo mobilizado pelo escarificador, nos ensaios a $275 \mathrm{~mm}$ de profundidade. Presume-se que, na região pontilhada, as tensões não são suficientes para cisalhar o solo, quando se opera com uma única haste porém, quando estão presentes duas ou mais hastes, a ação combinada de duas hastes adjacentes pode, então, produzir a ruptura do solo. Estas afirmações são coerentes com o trabalho de Lanças (1988) que avaliou hastes subsoladoras e concluiu que as montagens com hastes múltiplas ( 2 a 3 hastes) foram mais eficientes na perturbação do solo que as montagens com uma haste simples, de mesma forma geométrica.

A área perturbada, não considerada na equação de McKeys, pode resultar em diferenças consideráveis, principalmente quando o solo é bastante coeso e apresenta baixo teor de umidade por ocasião de seu preparo (valores inferiores ao limite de plasticidade). A predição desta área, no entanto, não é simples, uma vez que ela não depende somente de parâmetros geométricos.

As diferenças obtidas entre a EAP e os dados do experimento foram da ordem de $8 \%$. O fator de correção de 1,08 pode ser aplicado a ela para prever, com maior exatidão e a nível de campo, o valor da área de seção transversal de solo mobilizado, em situações similares àquelas nas quais o experimento foi realizado.

A eficiência do escarificador é dependente da relação espaçamento entre hastes e profundidade de trabalho (1/p). Os valores, em percentagem, obtidos no experimento, são representados na Figura 6. A literatura mostra que a melhor relação 1/p gira em torno de 1,5 (1 a 1,5 - Spoor \& Godwin, 1978; 1,4 \pm 0,25 - Godwin et al., 1984; 1,5 a 2 - Benez et al. , 1991). No 
presente trabalho, a eficiência do escarificador apresentou comportamento linear, crescente e significativo, em função da profundidade de operação, com coeficiente de determinação, para a média dos dados, de 0,93 . Os resultados obtidos demonstram que a eficiência aumentou com a redução da relação $1 / \mathrm{p}$.

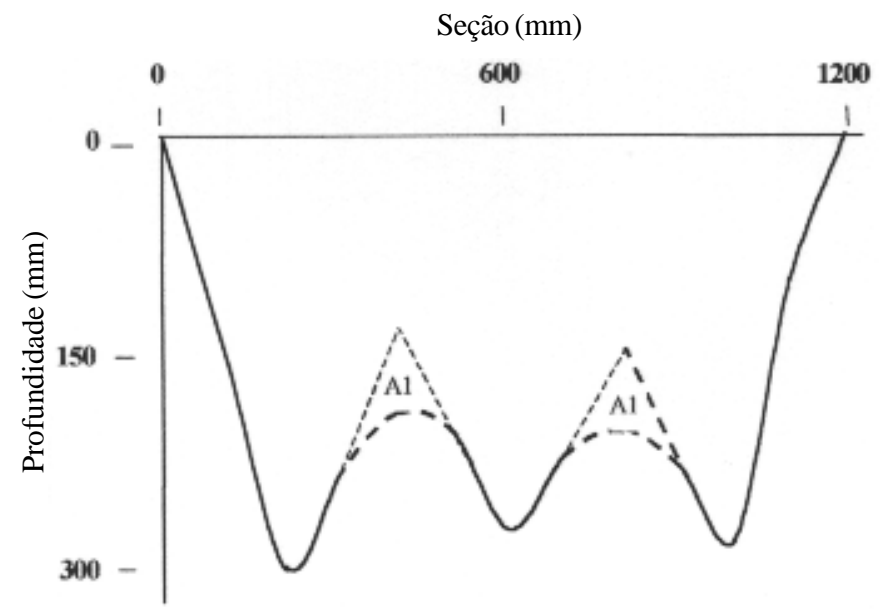

Figura 5. Perfil da seção transversal obtido para a área média do solo mobilizado na profundidade de $275 \mathrm{~mm}$. As áreas A1 determinadas pelas linhas pontilhadas representam a área perturbada, não considerada na equação de McKeys (1985)

Beltrame (1983) realizou um trabalho de avaliação de desempenho de três subsoladores em Latossolo VermelhoEscuro do Rio Grande do Sul, dentre os quais o modelo Jumbo, cujas hastes apresentam características construtivas semelhantes às utilizadas no presente trabalho. Os perfis de solo mobilizado, por ele apresentado, para o modelo Jumbo demonstram, para a profundidade de $350 \mathrm{~mm}$, que a distância entre hastes, de $460 \mathrm{~mm}(1 / \mathrm{p}=1,31)$ quando comparada com a distância de $330 \mathrm{~mm}(1 / \mathrm{p}=0,94)$ além de resultar em um aumento na largura de trabalho do implemento, produziu um perfil de fundo mais homogêneo, mesmo quando houve variação no teor de umidade. $\mathrm{O}$ autor concluiu que o teor de umidade do solo, quando inferior ao limite de plasticidade, produziu aumento relativo na área de solo mobilizado.

A melhor eficiência obtida neste trabalho, de 85,69\%, ocorreu na maior profundidade $(1 / \mathrm{p}=1,23)$; no entanto, na menor profundidade $(1 / \mathrm{p}=3,2)$ o escarificador apresentou eficiência de $77,94 \%$ que pode, a nível prático, ser considerada aceitável. A pequena diferença, embora significativa, encontrada nos ensaios, é observada na Figura 6, que mostra uma inclinação da reta obtida pela regressão, em relação ao eixo da variável independente, de apenas $2,3^{\circ}$. Desta forma pode-se afirmar que as hastes escarificadoras apresentaram boa eficiência em todas as relações $1 / p$ estudadas, quando o espaçamento entre haste estava fixo em $400 \mathrm{~mm}$ e o solo relativamente seco.

Esses resultados têm implicação prática muito grande, considerando- se que uma relação $1 / \mathrm{p}$ menor implica em uma capacidade operacional menor do implemento; assim, para a maximização do desempenho do escarificador não se pode ignorar os parâmetros distância entre hastes, teor de umidade do solo e da profundidade de trabalho, além da velocidade de

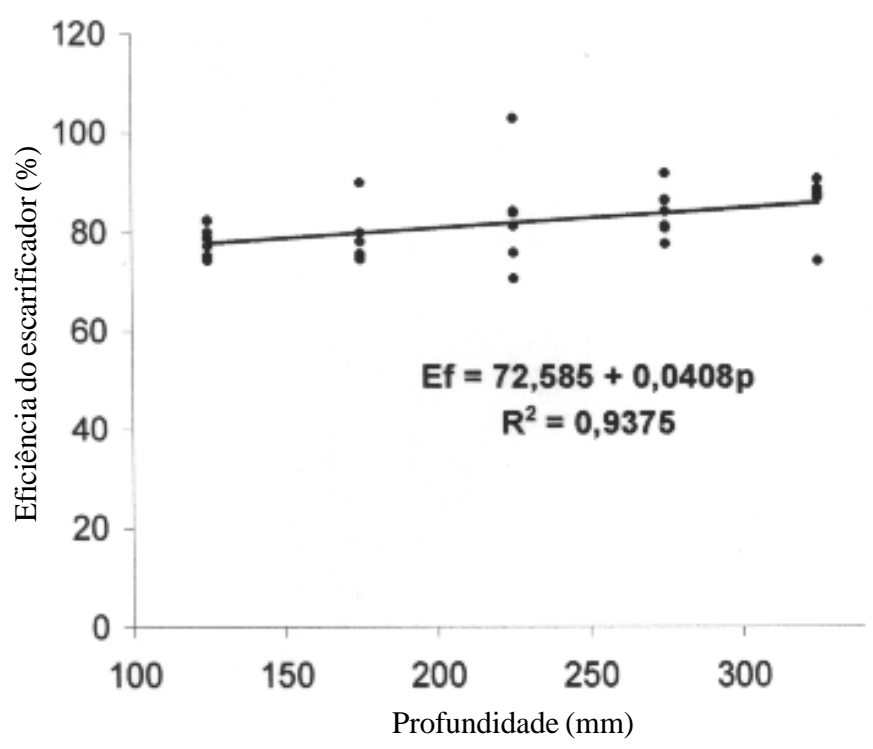

Figura 6. Eficiência do escarificador na mobilização do solo (\%) em função da sua profundidade de trabalho (p, em mm) com 3 hastes espaçadas de $400 \mathrm{~mm}$

operação, já discutida. A adequação desses parâmetros pode levar a uma alta capacidade operacional e qualidade elevada do trabalho realizado.

\section{CONCLUSÕES}

Com base nos resultados obtidos e se considerando as condições em que o experimento foi conduzido, pode-se concluir que:

1. A velocidade de operação não influenciou significativamente nos parâmetros força de tração, área de seção transversal de solo mobilizado, resistência específica e eficiência do escarificador.

2. A força exigida na barra de tração do trator, para cada haste do escarificador, espaçadas de $40 \mathrm{~cm}$, em função da profundidade de trabalho, tem comportamento quadrático e pode ser estimada pela seguinte expressão, onde F representa a força, em Newtons, e p a profundidade de operação, em milímetros:

$$
\mathrm{F}=3.231,33-25,13 \mathrm{p}+0,1 \mathrm{p}^{2}
$$

3. A equação de McKeys para a predição da área de solo mobilizado teve sua exatidão melhorada com o uso do fator 1,08 .

4. A área de seção transversal de solo mobilizado pelo escarificador apresentou comportamento linear, em função da profundidade de trabalho.

5. O escarificador utilizado apresentou boa eficiência na perturbação do solo relativamente seco, mesmo para uma relação $1 / \mathrm{p}=3,2$.

6. A regulagem do escarificador, com vistas a maximizar o seu desempenho, deve ser realizada observando-se criteriosamente os fatores umidade de solo, profundidade de trabalho, distância entre hastes e velocidade de operação.

\section{AGRADECIMENTOS}

À Escola Agrotécnica Federal de Cuiabá (Colégio Agrícola de São Vicente) pelo apoio logístico e de pessoal, sem os quais não seria possível a realização deste trabalho. 


\section{REFERÊNCIAS BIBLIOGRÁFICAS}

AMERICAN SOCIETY AGRICULTURALENGINEERS. ASAE Standard 1990. St Joseph, Michigan, 1990 (n.p.)

BELTRAME, L.F.S. Avaliação de desempenho de três subsoladores em latossolo vermelho-escuro. Engenharia Agrícola, Botucatu, v. 7, n. 1, p. 37-52. 1983.

BENEZ, S.H.; BICUDO, S.J.; LANÇAS, K.P. Subsolador: Influência do número de hastes, largura da sapata e profundidade de trabalho em alguns parâmetros relacionados à mobilização do solo. In: CONGRESSO BRASILEIRO DE ENGENHARIA AGRÍCOLA, 20, 1991. Londrina. Anais... Londrina: SBEA/IAPAR, Vol.2, 1991.p. 925-40

BIANCHINI, A.; MANTOVANI, E.; MARTIN, P.J. Avaliação de desempenho de um escarificador em solo aluvial. Agricultura Tropical, Cuiabá. v. 2, n. 1, p. 61-70. 1996.

FIGUEREDO, P.R.A. Avaliação de hastes de escarificador. In: CONGRESSOBRASILEIRODEENGENHARIA AGRÍCOLA, 23. Campinas, 1994. Paper no 94-4-73.

FUNDAÇÃO IBGE. Levantamento sistemático da produção agrícola - junho/1994. FUNDAÇÃO IBGE. Rio de Janeiro, v. 7, n. 6, p. $1-69,1994$.

GODWIN, R.J.; SPOOR, G. \& SOOMRO, M.S. The effect of tine arrangement on soil forces and disturbance. Journal of Agricultural Engineering Research., London, v. 30, p. 47-56, 1984.

GOMES, F.P. Curso de estatística experimental, 13 ed. Piracicaba, Nobel, 1990.468p.

KISS, G.C.; BELLOW, D. An analysis of forces an cultivator sweeps and spikes. Canadian Agricultural Engineering, Saskatoon, v. 23, n. 2, p. 77-83, 1981.

LANÇAS, K.P. Subsolador: Desempenho em função de formas geométricas de hastes, tipos de ponteira e número de hastes. Botucatu: UNESP, 1988. Tese Doutorado
MAIA, J.C. Influência de tipos de preparo sobre algumas características físicas e comportamento da soja (Glycine max L.) em solo sob vegetação de cerrado. Santa Maria: UFSM, 1990. 132p. Dissertação Mestrado

MANTOVANI, E.C. Compactação do solo. Informe Agropecuário, Belo Horizonte, v. 13, n. 147, p. 52-5, 1987.

McKEYS, E. Soil cutting and tillage. Oxford: Elsevier, $1985.217 \mathrm{p}$.

ORTIZ-CAÑAVATE, J.; HERNANS, J.L. Técnica de la mecanizacion agraria. 3 ed. Madrid, Mundi-Prensa, 1989. 641p.

OWEN, G.T. Soil sailing forces and tool speed in compact soils Canadian Agricultural Engineering, Saskatoon, v. 31, p. 15-20. 1989.

PERUMPRAL, J.V.; GRISSO, A.D.; DESAI, C.S. A soil- tool model based on limit equilibrium analysis. Transaction of the ASAE, St. Joseph, v. 26, p.991-5. 1983.

PORTELA, J.A.; FAGANELO, A.; SATIELER, A. Desempenho operacional de hastes subsoladoras. In: CONGRESSO BRASILEIRODEENGENHARIA AGRÍCOLA, 23. Campinas, 1994. Paper no 94-4-3.

SILVA, A.P.; LIBARDI, P.L.; CAMARGO, O.A. Influência da compactação nas propriedades físicas de dois Latossolos. Revista Brasileira de Ciência do Solo, Campinas, v. 10, p. 91-95, 1986.

SILVA, J.R.; KURACHI, S.A.H.; MESQUITA, C.M.;BARRETO, J.N.; PETRONI, A.C. Correlação entre esforços de tração e profundidade de subsolagem. Bometim Técnico no 96. Campinas: Instituto Agronômico de Campinas, 1984. 18p.

SPOOR, G.; GODWIN, R.J. An experimental investigation in the dup haseming of by rigid times. Journal of Agricultural Engineering Research, London, v. 23, p. 243-58.1978

STOLF, R.; FERNANDES, J.; FURLANI NETO, V.L. Recomendações para uso do penetrômetro de impacto, modelo IAA/Planalsucar-Stolf, Piracicaba. Ministério da Indústria e do Comércio - Instituto do Açúcar e do Álcool Planalsucar, 1983. 